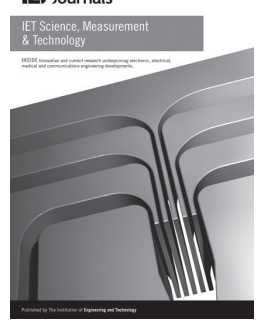

ISSN 1751-8822

\title{
Wireless sensor network-based solution for environmental monitoring: water quality assessment case study
}

\author{
Octavian Postolache ${ }^{1}$, José Dias Pereira², Pedro Silva Girão 3 \\ ${ }^{1}$ Instituto de Telecomunicações, DCTI/ISCTE-IUL, Lisbon, Portugal \\ ${ }^{2}$ Instituto de Telecomunicações, DSI/EST/IPS, Setubal, Portugal \\ ${ }^{3}$ Instituto de Telecomunicações, DEEC/IST/UL, Lisbon, Portugal \\ E-mail: opostolache@Ix.it.pt
}

\begin{abstract}
The challenges of climate change, population growth, demographic change, urbanization and resource depletion mean that the world's great cities need to adapt to survive and thrive over the coming decades. Slashing greenhouse gas emissions to prevent catastrophic climate change, while maintaining or increasing quality of life, can be a costly and difficult process. Two factors that directly affect the life quality in the XXI century cities are the water and air quality that can be monitored using the combination of low cost sensing modules, machine to machine (M2M) and internet of things (IoT) technologies. In this context, this study presents a wireless sensor network architecture that combines low cost sensing nodes and a low cost multiparameters sensing probe for reliable monitoring of water quality parameters of surface waters (lakes, estuaries and rivers) in urban areas. A particular attention is dedicated to the design of the conductivity, temperature and turbidity signal conditioning circuits, highlighting important issues related to linearisation, measuring dynamic range and low-cost implementation by using commercial off-the-shelf components and devices. Several issues related to the wireless sensor network implementation are included in this study, as well as several simulation and experimental results.
\end{abstract}

\section{Introduction}

Smart cities, in the current worldwide information and communication technology applications scenario, imply a constantly growing number of ever more powerful internet connected devices (smartphones, sensors, household appliances, radiofrequency identification (RFID) devices and so on) and an increasing use of low cost sensors that can deliver information to increase the quality of life. Concerning the concept of smart cities, different approaches are presented in the literature. One of these approaches, developed by IBM [1], includes several pillars, some of them related with environmental monitoring, energy and water, healthcare and smarter buildings, among others. In this context, water resources are a limited resource that requires a careful use, and monitoring its quality is a very important task, regardless of the purpose for which water is used. Thus, the development of ubiquitous solutions for water quality (WQ) assessment will have a huge application in the future, and low-cost sensing solutions and wireless sensing networks must be developed to integrate measurement data. Concerning personalised health care, indoor and outdoor air quality are also important parameters that can be used for instance to correlate clinical data with environmental conditions. Moreover, respiratory distress is the second most common symptom of adults transported by ambulance and is associated with a relatively high overall mortality, of $18 \%$, before hospital discharge [2-4]. Several solutions have been proposed in the area of air quality monitoring [5-7]. Measuring systems to monitor the concentration of gases such as $\mathrm{NO}_{2}, \mathrm{CO}$ and the evolution of physical parameters such as relative humidity $(\mathrm{RH})$ and temperature $[8,9]$ have been deployed.

Air quality and surface WQ should often be considered together because of the relation between them. The best example of a direct link between air pollution and water pollution is acid rain. Acidic gases $\left(\mathrm{NO}_{x}\right.$ and $\left.\mathrm{SO}_{x}\right)$ are emitted into the air by various sources. They combine with water in the air to form sulphurous and nitrous acids which then fall as rain to contaminate water in rivers and lakes by decreasing the $\mathrm{pH}[10,11]$. The acidic water leaches metals out of the rocks and sediments as soluble ions. These increase heavy metal (arsenic, lead and so on) levels in the water. Taking into account these interrelations and also the health protection of the people that use the water for daily activity and for recreation, the existence of distributed measuring systems for on-line monitoring of the quality of water with capability to transmit the information using client-server architectures, including mobile technology, still represents a challenge nowadays.

Considering the example of air quality sensor architectures that were deployed in different cities in the last years [12], one of the conditions to assure a quick implementation is low price of the system. Another important condition is the 
capability of the system of monitoring the environment parameters in extended areas. In this context, we considered the development of a system that can provide information about the changes in the quality of water through the measurement of electrical conductivity, temperature and turbidity. Through the measurements of these variables we can detect changes in water environments and study if the causes of those modifications are natural or not, like in the case of pollution. For extended information about the WQ when pollution events are detected, it shall be possible to add to the system multi-parameter WQ probes such as Hydrolab Quanta Multiparameter Sonde [13] or the Rosemount Analytical Model 1057 Multiparameter Analyser [14] for higher flexibility and interoperability.

Taking into account the above mentioned considerations, a WQ sensing module with conductivity, temperature and turbidity measuring channels was designed and implemented. Each sensing module is attached to a wireless sensor node equipped with primary data processing and wireless communication capabilities.

Referring to the conductivity measuring channel, a two electrode cell was used because of its simplicity, but also because it is easy to clean and it covers the desired measuring range $0.1-20 \mathrm{mS} / \mathrm{cm}$ [15]. The temperature compensation associated to the conductivity measuring probe is based on the temperature information delivered by the temperature measuring channel that is expressed by a negative temperature coefficient (NTC) thermistor and an appropriate conditioning circuit. The turbidity measuring channel was materialised using two detectors associated with the measurement of transmitted and scattered light emitted by a light source [16].

The signals provided by the measuring channels are acquired, processed and transmitted by an NI-WSN (wireless sensor module) sensor node from National Instruments, through a gateway to a host computer internet connection that provides a WQ monitoring service using LabVIEW web server capabilities. Several signal processing algorithms can be implemented on the host computer including global representation of WQ evolution for the monitored area, pollution events signalling, short term and long term WQ prediction.

\section{WO sensing node and networking}

The sensing module associated to each node of the wireless sensor network for urban WQ monitoring is able to measure water electrical conductivity, temperature and turbidity and is connected to the NI analogue input block of the NI WSN-3202 (Fig. 1).

The four bidirectional digital channels that are included in the NI-WSN can be used for several purposes, such as, defining the gain of the signal conditioning programmable gain amplifiers or to supervise faulty conditions of the measuring system, like low supply voltage amplitude or voltage pin amplitudes out of scale. Others important characteristics of the NI-WSN node that dictate its choice include a very low-power consumption, being possible to achieve 3 year of autonomy using 4 AA batteries, a maximum bit rate and sample rate of $250 \mathrm{kbit} / \mathrm{s}$ and $1 \mathrm{~S} / \mathrm{s}$, respectively, $300 \mathrm{~m}$ wireless coverage range without repeaters, and interoperability with others wireless devices such as routers and gateways. It is also important to underline that an outdoor enclosure can be used in each sensing node in order to improve its reliability, which is a

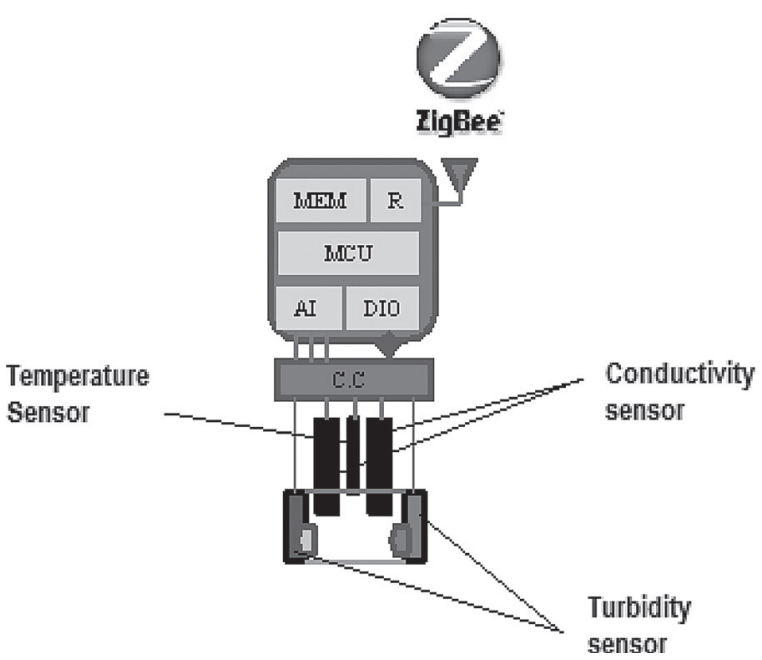

Fig. 1 Block diagram of the WQ sensing node

$\mathrm{CC}$ - conditioning circuit, AI - analogue front end, DIO - digital input output, MCU - low power microcontroller, MEM - flash memory and R IEEE802.15.4 transceiver

key feature in this type of measuring systems that are submitted to harsh working conditions. The implemented measuring channels are designed to provide the information regarding pollution (acid rain, polluted water discharge that can affect the values of conductivity from $\mu \mathrm{S} / \mathrm{cm}$ to $\mathrm{mS} / \mathrm{cm}$ ) or to monitor estuarine tidal and associated natural phenomena by measurement of temperature, conductivity and turbidity parameters.

\subsection{Conductivity measuring channel}

The electrical conductivity of a water solution reflects the ability of the solution to conduct an electric current and it depends on the amount of ions present in the solution. In the present case, two-electrode cell architecture was implemented to perform conductivity measurements. One important parameter of cell is the so-called 'cell constant' which is the relation between the distance between the electrodes and their area determined by their geometric shape. The cell geometry was designed to allow a $0.1-20 \mathrm{mS} / \mathrm{cm}$ measuring range. The conductivity measuring channel includes two main sub-circuits, one that contains an oscillator, an active bridge amplifier and a difference amplifier, and the other sub-circuit that contains a precision half-wave rectifier, a low-pass filter and a non-inverter amplifier. Both sub-circuits, 1 and 2, are represented in Figs. 2 and 3, respectively.

In order to avoid the polarisation phenomena and to minimise double layer effects $[17,18]$, the voltage applied

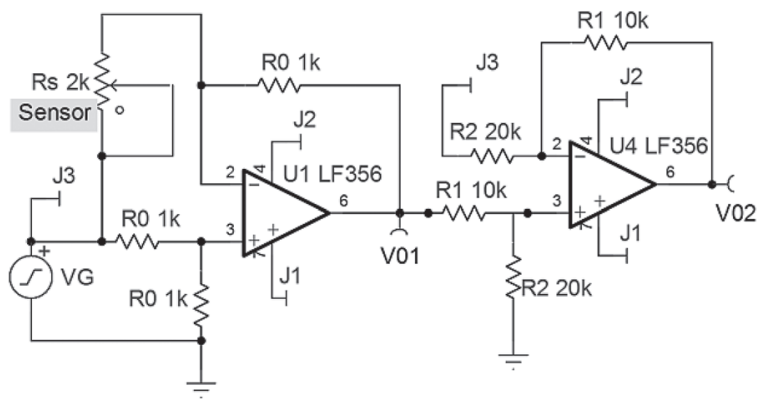

Fig. 2 Conductivity signal conditioning: sub-circuit 1

Wheatstone bridge amplifier and difference amplifier 


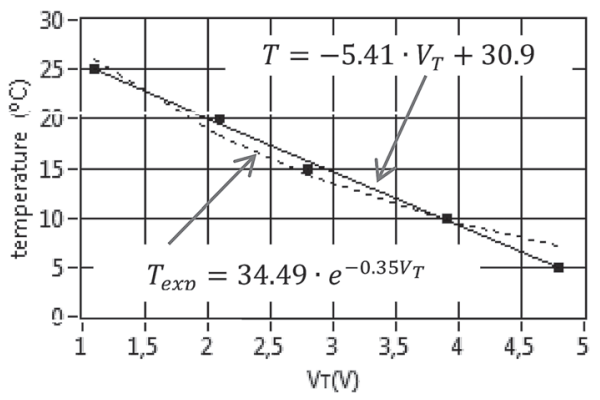

Fig. 10 Characteristic curve of a temperature input channel $V_{T}$ - acquired voltage on temperature channel for different standard temperatures

are calculated from the voltage values output by the conductivity measuring channels.

The temperature characteristic curve in Fig. 10 was obtained using an oven with temperature control to impose the calibration points and to obtain the data required to calculate the linear regression of the temperature measuring channels characteristic.

For the calibration of the turbidity measuring channels, four formazin turbidity standard solutions of 10, 100, 200 and $400 \mathrm{NTU}$ were used, since formazin solutions are reference material for turbidity instrument calibration. After the turbidity coefficients are calculated, the turbidity characteristic curve and the corresponding linear approximation are obtained (Fig. 11).

Based on calibrated measuring channels associated to each WQ-WSN-Ei, several measurements and data communication tests were carried out. The values of the conductivity measuring channel with temperature compensation associated to WSN-E1 obtained in a laboratory measuring session are presented in Table 1 . The accuracy obtained was $2 \%$ FS $(0-15 \mathrm{mS} / \mathrm{cm})$.

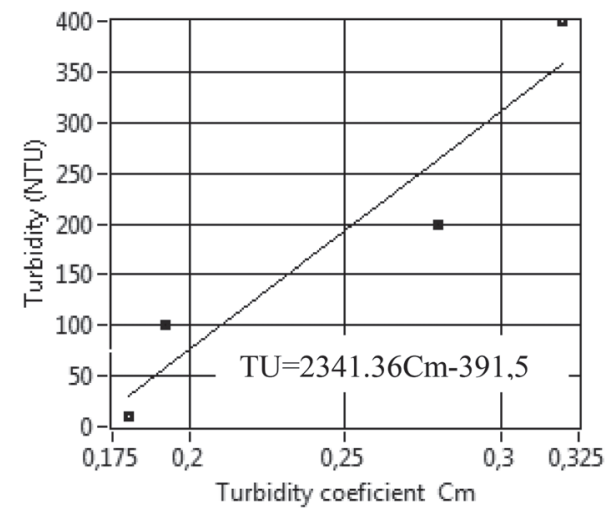

Fig. 11 Characteristic curve of a turbidity measuring channel

Table 1 Conductivity results (full-scale: $15 \mathrm{mS} / \mathrm{cm}$ )

\begin{tabular}{lrrr}
\hline $\begin{array}{l}\text { Percentage of } \\
\text { span, \% }\end{array}$ & $\begin{array}{c}\text { Ref. value, } \\
\mu \mathrm{S} / \mathrm{cm}\end{array}$ & $\begin{array}{c}\text { Measured value, } \\
\mu \mathrm{S} / \mathrm{cm}\end{array}$ & $\begin{array}{c}\text { Error, \% } \\
\mathrm{FS}\end{array}$ \\
\hline 0 & 0 & 90 & 1 \\
25 & 3930 & 3827 & 1 \\
50 & 7610 & 7698 & 1 \\
75 & 11520 & 11594 & 1 \\
100 & 15000 & 15368 & 2 \\
\hline
\end{tabular}

Tests on temperature and turbidity measuring channels revealed accuracy values of $1 \% \mathrm{FS}\left(5-25^{\circ} \mathrm{C}\right)$ and $5 \% \mathrm{FS}$ (0-400 NTU), respectively.

\section{Conclusions}

This paper presents the design and implementation of surface water real-time monitoring based on a ZigBee wireless sensor network.

An important part of the work includes the development of a low cost multi-parameter WQ measuring probe attached to the wireless sensor node. Thus, it was designed, implemented and tested a conductivity measuring channel characterised by a two-electrode cell in combination with a temperature measuring channel. The proposed conditioning circuit used in conductivity measuring channel is based on a Wheatstone bridge amplifier and provides an output voltage that linearly depends on conductivity. The probe also includes a turbidity measuring channel whose working principle is based on a set of two infrared optical emitters and detectors pairs that provide the detection of the transmitted and scattered light caused by the particles in suspension in the water. The limited number of WQ measurement sensors associated with wireless sensor nodes and the necessity to perform periodic verification/calibration of the sensors can be considered as a drawback of the presented solution. The last problem can be solved with the inclusion of an in-situ calibration system associated with WQ measuring channels. A prototype of this kind of system was developed and reported by the authors in the past. The inclusion of a field calibrator will imply additional costs and will affect the autonomy of the distributed measurement system of WQ parameters.

The laboratory tests of the implemented WQ-WSN proved the capability of the system to provide accurate WQ information. Future developments of the proposed measurement system will consider the inclusion of additional sensing devices and the analysis of reliability issues related with the usage of other conductivity cell types, such as, four electrode or inductive cells, that are less sensitive to external working conditions.

\section{References}

1 IBM, Smarter Cities, on-line at http://www.ibm.com/smarterplanet/us/ en/smarter_cities/overview/index.html

2 Postolache, O., Girão, P.S., Ferraria, G., Barroso, N., Pereira, J.M.D., Postolache, G.: 'Indoor monitoring of respiratory distress triggering factors using a wireless sensing network and a smart phone'. Int. Instrumentation and Measurement Technology Conf. 2009 (I2MTC'2009), Singapore, May 2009, pp. 451-456

3 Stiel, I.G., Spaite, D.W., Field, B., et al.: 'Advanced life support for out-of hospital respiratory distress', NEJM, 2007, 356, (24), pp. $2156-64$

4 Rabe, K.F., Hurd, S., Anzuento, A., et al.: 'Global strategy for the diagnosis management, and prevention of chronic obstructive pulmonary disease: GOLD executive summary', Am. J. Respir. Crit. Care Med., 2007, 176, (6), pp. 532-55

5 Indoor air quality impacts child asthma, Humidex Reduces contaminates that trigger asthma attacks: http://www.naturalnews.com/010255.html

6 Tomizuka, M., Yun, C.B., Giurgiutiu, V.: 'A smart indoor air quality sensor network'. Proc. SPIE, Smart Structures and Materials, 2006, vol. 6174 , pp. $1277-1290$

7 Ulivieri, N., Distante, C., Luca, T., Rocchi, S., Siciliano, P.: 'IEEE1451.4: a way to standardize gas sensor', Sensors Actuators B, Chem., 2006, 114, (1), pp. 141-151

8 Bielsa, A.: 'Libelium world:smart city project in Salamanca to monitor air quality and urban traffic', available at: http://www.libelium.com/ smart_city_air_quality_urban_traffic_waspmote/ 


\section{www.ietdl.org}

9 Postolache, O., Pereira, J.M.D., Girão, P.: 'Smart sensors network for air quality monitoring applications', IEEE Trans. Instrum. Meas., 2009, 58, (9), pp. 3253-3261

10 González, C.M., Aristizábal, B.H.: 'Acid rain and particulate matter dynamics in a mid-sized Andean city: the effect of rain intensity on ion scavenging', Atmos. Environ., 2012, 60, pp. 164-171

11 Beverland, I.J., Heal, M.R., Crowther, J.M., Srinivas, M.S.N.: 'Real-time measurement and interpretation of the conductivity and $\mathrm{pH}$ of precipitation samples', Water Air Soil Pollut., 1997, 98, (3-4), pp. 325-344

12 Coren, M.J.: 'The air quality egg will let you know exactly what you're breathing' available at: http://www.fastcoexist.com/1679740/the-airquality-egg-will-let-you-know-exactly-what-youre-breathing

13 'Hydrolab Quanta Multiparameter Sonde', http://www.hachhydromet. com/web/ott_hach.nsf/id/pa_quanta.html, 2012

14 'Rosemount Analytical Model 1057 Multiparameter Analyser', www2. emersonprocess.com/en-US/brands/rosemountanalytical/Liquid/

15 Torrent, J.: 'Low-cost conductivity cells for water measurement purposes'. IMTC 2004-Instrumentation and Measurement Technology Conf., Como, Italy, 18-20 May 2004

16 Postolache, O., Girão, P., Pereira, J.D., Ramos, H.G.: 'Multibeam optical system and neural processing for turbidity measurement', IEEE Sensors J., 2007, 7, (5), pp. 677-684
17 Mutoh, N., Inoue, T.: 'A control method to charge series-connected ultraelectric double-layer capacitors suitable for photovoltaic generation systems combining MPPT control method', IEEE Trans. Ind. Electron., 2007, 54, (1), pp. 374-383

18 Korthum, G.: 'Treatise on electrochemistry' (University of Tubingen, Germany, 2nd edn. by American Elsevier Publishing, New York, 1965)

19 Pereira, J.M.D., Postolache, O., Girão, P.: 'PWM-A/D conversion: a flexible and low-cost solution for transducer linearization'. Proc. ISA IEEE - SIcon01, Rosemount, Illinois, EUA, November 2001, pp. 258-263

20 Pereira, J.M.D., Postolache, O., Girão, P.S.: 'A digitally programmable $\mathrm{A} / \mathrm{D}$ converter for smart sensors applications', IEEE Trans. Instrum. Meas., 2007, 56, (1), pp. 158-163

21 ZigBee Alliance, Control your world, available at: http://www.ZigBee. org

22 Pereira, J.M.D., Postolache, O., Girão, P.: 'Spread spectrum techniques in wireless communication', IEEE Instrum. Meas. Mag., 2009, 12, (6), pp. 21-24

23 Postolache, O., Pereira, J.M.D., Girão, P.M.: 'Geenhouses microclimate real-time monitoring based on a wireless sensor network and GIS'. Proc. IMEKO World Congress, Busan, Korea, South, September 2012, Vol. 1, pp. $1-5$ 